\title{
UM OLHAR PARA A SUBVERSÃO DOS DITAMES DE GÊNERO NA LITERATURA INFANTIL
}

\author{
UNA MIRADA PARA LA SUBVERSÍON DE LOS DICTÁMES DE \\ GÉNERO EM LA LITERATURA INFANTIL
}

\section{A LOOK TO THE SUBVERSION OF GENDER DICTATES IN CHILDREN'S LITERATURE}

\author{
Edimauro Matheus Ramos ${ }^{1}$ \\ Aracely Mehl Gonçalves ${ }^{2}$
}

\section{RESUMO}

Esta pesquisa parte da revisão bibliográfica pertinente ao gênero no viés da educação e busca discutir as relações de gênero no espaço da Educação Infantil. No tocante ao gênero, voltamos os olhares para três livros da literatura infantil que desestabilizam estereótipos através de personagens e situações desgenderizadas.

PALAVRAS-CHAVE: Gênero. Literatura Infantil. Heteronormatividade. Subversão.

\section{RESUMEN.}

Esta investigación parte de la revisión bibliográfica pertinente al género en el sesgo de la educación y busca discutir las relaciones de género en el espacio de la Educación Infantil. En cuanto al género, volvemos las miradas a tres libros de la literatura infantil que desestabilizan los estereotipos a través de personajes y situaciones desgendidas.

PALABRAS-CLAVE: Género. Literatura Infantil. Heteronormatividad. Subversión.

\section{ABSTRACT}

This research starts from the bibliographic review pertinent to gender in the education bias and it seeks to discuss gender relations in the area of Children's Education. With regard to gender, we turn our eyes to three books of children's literature that desestabilize stereotypes through degenerated characters and situations.

KEYWORDS: Gender. Children's Literature. Heteronormativity. Subversion.

\footnotetext{
${ }^{1}$ Acadêmico de Pedagogia das Faculdades Integradas de Itararé (FAFIT).

2 Professora Mestre e Coordenadora do Curso de Pedagogia das Faculdades Integradas de Itararé (FAFIT).
} 


\section{Introdução}

A Educação Infantil, não diferente de qualquer modalidade educativa, é atravessada pelos gêneros. Mas não raro, deparamo-nos com expressões que limitam meninos e meninas às justificativas biológicas, agindo rigorosamente sobre essas genderizações ${ }^{3}$ que tornam esse espaço passível de estranhamentos às expressões que fogem das fronteiras heteronormativas.

Porém, ferramentas e alternativas educativas para a subversão das fendas de uma pedagogia disciplinadora carecem de otimizações que harmonizem esses diálogos com as infâncias e suas singularidades. A literatura infantil, nesse espectro, tem produzido algumas obras que se deslocam desses parâmetros de gênero numa perspectiva e reflexiva e questionadora.

A presente pesquisa se estrutura através da revisão bibliográfica pertinente ao conceito de gênero na educação e da análise dos livros infantis "Olivia não quer ser princesa", de Ian Falcolner, "Ceci e o vestido do Max", de Thierry Lenain e "Menina não entra", de Telma Guimarães Castro Andrade.

\section{A problematização e a subversão das relações de gênero nos livros infantis}

As nuances performativas do termo gênero vêm do movimento feminista e da corrente do pós-estruturalismo ${ }^{4}$. Abrindo espaço para os Estudos de Gênero, tais vertentes estudam as relações de poder inscritas nas heterogeneidades étnico-raciais, sexuais, de gênero e entre outras. Butler $(2003)^{5}$ encabeçou essas articulações pósestruturalistas ao problematizar o binarismo e o atrelamento do gênero ao sexo e as características que o legitimam.

Contextualizando com a Educação Infantil, o desconhecimento dessa noção de gênero impulsiona a categorização do que deve ser direcionado apenas para as meninas e para os meninos, reforçando protótipos de masculinidade e feminilidade através de abordagens sexistas, misóginas, homofóbicas e sexualizadas (a erotização precoce do corpo feminino, por exemplo), estabelecendo fronteiras entre os gêneros na infância.

${ }^{3}$ O corpo e o gênero tidos como índices de separação. Le Breton (2010, p. 30-31) acredita que o "corpo funciona como se fosse uma fronteira viva para delimitar, em relação aos outros, a soberania da pessoa." ${ }^{4}$ Para Williams (2012), é uma visão que contesta e se opõe a qualquer certeza de natureza absoluta e desconsidera limites para o conhecimento.

${ }^{5}$ Butler (2003, p. 24), nessa ótica, nos diz que "se o gênero são os significados culturais assumidos pelo corpo sexuado, não se pode dizer que ele decorra de um sexo desta ou daquela maneira". 
Desestabilizar essas masculinidades e feminilidades no cotidiano da Educação Infantil requer disposição para reconhecer o prejuízo e a implicação desses arranjos de gênero rumo a uma pedagogia da diversidade.

Ao pensar sobre ferramentas pedagógicas pertinentes à modalidade em questão, os olhares desta pesquisa se voltam para alguns livros infantis que têm delineado um outro olhar sobre esses atributos.

Ponderando sobre o enredo de três livros infantis com tal finalidade, foi possível identificar que cada um deles traz no seu seio: a desconstrução da noção de feminilidade, a fuga dos estereótipos atribuídos aos esportes e atividades, idealizações de uma masculinidade tóxica, machismo e o questionamento dessas normas.

Em "Olivia não quer ser princesa" (2014), de Ian Falconer, imergimos no universo de uma porquinha inconformada que contesta seus pais por sempre associarem a imagem das garotas com as princesas e a inocência. Ao decorrer do livro, Olivia vai quebrando paradigmas ao vestir-se fora desses padrões e desabafa:

- Acho que estou com crise de identidade - ela disse para os pais.

- Bem - disse o pai -, você será a minha princesa!

- É esse o problema - disse Olivia - todas as meninas querem ser princesas. [...] (p. 4-5)

- Por que só tem princesa cor-de-rosa? Por que não tem princesa da Índia, princesa da Tailândia, princesa da África ou princesa da China? Existem alternativas (p. 8-9)

No livro "Ceci e o vestido do Max", de Thierry Lenain (2010), Ceci também está cansada desses clichês de "coisas de menina" e não se vê, de jeito nenhum, dentro de um vestido que Max, seu namorado, achou bonito. De maneira lúdica, o livro esboça muito bem a fuga e o reforço das ideias de feminilidade e masculinidade:

"No meio das bolas de plástico, tem uma dourada e de couro que é muito cara. Ceci sonha com essa bola desde a primeira vez em que a viu. E continua sonhando até hoje:

— Com uma bola, dessas eu faria todos os gols do mundo!” (p. 6)

“ - Tudo bem, Max, vou experimentar o vestido só para agradar você... Mas só depois que ...

Max pergunta:

— Depois do quê?

Ela responde, agora no escuro:

- Depois de você.

Max quase tem um troço. 
— Está louca? Eu sou um menino! Não posso colocar esse vestido! ” (p. 17-19)

Por fim, "Menina não entra" (2010) pontua o sexismo e a masculinização do futebol, narrando a história de um time formado por garotos que, ao precisar de um jogador a mais, cogitam colocar Fernanda, a qual, primeiramente, sofre represália por querer jogar em um esporte "de meninos”. Após verem a ascensão dela, a mesma se torna a capitã do time.

Para além de apenas ferramentas que agem em interface com a aprendizagem, a alfabetização, o letramento e a competência leitora, essas obras que se inclinam dos estereótipos e genderizações, numa proposta transdisciplinar, para Silveira (2005):

[...] vêm tomar o posto das obras pedagogizantes, castradoras e, abordando temáticas mais próximas ao cotidiano dos leitores e menos cerceadas por preocupações moralistas clássicas, serviriam duplamente para uma abertura crítica de suas mentalidades. (p. 117)

No entanto, só a leitura e exposição dos livros e de suas narrativas não serão suficientes ou erradicarão as relações de gênero e seus marcadores, muito menos fará com que outros professores se apropriem dessa visão. É imprescindível que a história tenha significância através da reflexão posterior à leitura, incitando questionamentos e inquietações, contornando-as em novas sínteses. Lins, Machado e Escoura (2016) estabelecem um norte para essas reflexões:

E se a menina não se sentir bem de batom? Ou o menino odiar futebol? Qual a consequência de dizer que a força é uma característica dos meninos? Significa que as mulheres não podem ser fortes? Ou ainda, que meninos podem usar a força para obter aquilo que desejam? (p.10)

Propondo a problematização dessas relações, os livros infantis que transportam essas posturas desgenderizadas para suas narrativas estão longe de ser meros recursos sem preceitos reflexivos, pois podem indagar e se contrapor aos perfis presentes nas narrações e nos personagens, destacando a importância do diálogo entre gênero, identidade e a Educação Infantil de maneira transversal e possível.

\section{Considerações finais}


Perante à problemática exposta, a percepção da literatura infantil voltada às propostas de gênero se amplia a partir das obras analisadas, permitindo que, através da fantasia, o docente possa viabilizar meios para garantir que meninos e meninas da Educação Infantil se expressem sem os enquadramentos das balizas de gênero.

Os livros infantis que se contrapõem aos enredos normativos permitem que a criança e os próprios docentes saiam de uma posição passiva e engendrada, propondo a reescrita desses ditames sob o olhar da transdisciplinaridade.

Neste cenário contemporâneo marcado por regimes de exceção, onde obras, como as que foram citadas acima, assombram as camadas essencialistas e conservadoras, a figura do professor é vital para cruzar essas limitações de forma consciente, plural, autônoma e cada vez mais resistente à rótulos, à intolerância, às falácias e às mordaças.

\section{Referências}

ANDRADE, Telma Guimarães Castro. Menina não entra. São Paulo: Editora do Brasil, 2010.

BUTLER, Judith. Problemas de gênero: feminismo e subversão da identidade. Tradução de Renato Aguiar. 15a edição. Rio de janeiro: Civilização Brasileira, 2003.

FALCONER, Ian. Olivia não quer ser princesa. $1^{a}$ ed. São Paulo. Editora Globo, 2014.

LE BRETON, David. A sociologia do corpo. Tradução de Sônia M.S. Fuhrmann. Petrópolis. Vozes, 2010.

LENAIN, Thierry. Ceci e o vestido do Max. $1^{\text {a }}$ ed. São Paulo: Companhia das Letrinhas, 2013.

LINS, Beatriz Accioly; MACHADO, Bernardo Fonseca; ESCOURA, Michele. Diferentes, não desiguais: a questão do gênero na escola. São Paulo: Reviravolta, 2016.

SILVEIRA, Rosa Hessel. Leitura, Literatura e Currículo. In: COSTA, Marisa Vorraber. O currículo nos limiares do contemporâneo. Rio de Janeiro: DP\&A, 2005.

WILLIAMS, James. Pós-estruturalismo. Petrópolis, RJ: Vozes, 2012.

Recebido em Novembro de 2018. Aprovado em Dezembro de 2018. 